\title{
Flexible and Affordable Foreign Language Learning Environment based on Web 2.0 Technologies
}

\author{
http://dx.doi.org/10.3991/ijet.v8i2.2488 \\ C. Gütl ${ }^{1,2}$, V. Chang ${ }^{2}$, A. Edwards ${ }^{3}$ and S. Boruta ${ }^{1,2}$ \\ ${ }^{1}$ Graz University of Technology, Graz, Austria \\ ${ }^{2}$ Curtin University, Perth, Australia \\ ${ }^{3}$ University of Colima, Colima, Mexico
}

\begin{abstract}
Web technologies and educational platforms have greatly evolved over the past decade. One of the most significant factors contributing to education on the Internet has been the development of Web 2.0 technologies. These technologies, socially interactive in nature, have much to contribute to the area of Computer Assisted Language Leaning. Unfortunately, Web 2.0 technologies for the most part have been used in an ad hoc manner, permitting language learners acquire knowledge through interaction, but not through a more structured manner as these technologies were not developed to help lean languages as such. The goal of our work is to research and develop an environment, which employs Web 2.0 technology plus online language learning tools to provide a more integrated language learning environment. This paper will explore the technologies and provide information about how tools can be better integrated to provide a more productive working environment for language learners. A first working proof of concept based on our approach introduced is promising supporting modern language requirements and first findings and space for improvements are discussed.
\end{abstract}

Index Terms-Second Language Learning, Computer Assisted Language Learning, e-Education, Flexible Learning Environment, Guided and Unguided Learning

\section{INTRODUCTION}

In the beginning of the $21^{\text {st }}$ century, our modern society lays a huge burden on its members. They have to cope with rapid changes in virtual all parts of their life, from technology to economic to financial changes. Globalization asks for many more knowledge and skills to compete in a rough, fast and widely open market. Education must prepare our society to cope with these demanding expectations not only to have proper knowledge and skills but also to have the right attitudes and willingness to continuously adapt in this fast changing world.

Competing in a globalized world requires strong foreign language skills which must go far beyond traditional foreign language learning in primary and secondary education. Modern language teaching and learning environments are increasingly employing technology across disciplines as bilingual education programs, at least in the United States, now employ modern technological means to teach both English and native language skills in model that not only maintains the mother tongue of immigrants, but increases skills in that language to help teach English skills. Reading, for instance, is reading. Once one can read in one language, the skills are directly transferable to the second language. Furthermore, English as a Second (taught primarily in countries where English is the native language) and English as a Foreign Language (taught primarily in countries where other languages are native) now employ web resources to present native speakers interacting in a natural manner, using natural language in native contexts. In this way, students can gain greater insight into how the cultural context affects the type of language used as well as socially appropriate (or inappropriate) behaviors. Most important, language learners using Web 2.0 technologies can now interact with natives when it was previously impossible and interact with them in ways that are motivating and non-threatening. In general Information and Communication Technologies and more specifically computer media have supported foreign language learning for a long time.

A simple and direct definition of Computer-Assisted Language Learning (CALL) is "the search for and study of applications of the computer in language teaching and learning" [35]. Over the last 30 years CALL has evolved from the most basic word processing software to state-ofthe- art virtual reality environments, intelligent systems, adaptive learning environments, expert systems, etc. One very important thing to consider, however, is that CALL is a field that is as new as the technological applications and technologies that support it. In other words, as technology and applications advance, their integration into the teaching and learning of languages is never far behind.

In fact, the potential of CALL is driven to a great degree even to this day by developments in the areas of hardware and software development, wireless and mobile technologies, multimedia support (including encoding, decoding and compression) and bandwidth considerations, especially bandwidth, latency and quality of services (QoS). What is certain, however, is that computer-assisted language learning will continue to develop in all areas of language instruction: speaking, listening, reading, writing, grammar, pronunciation, vocabulary, and cultural and linguistic competence, to name some of the most important. [26]

Consequently, CALL is limited to a great degree by developments in the area of hardware and software development and it evolves to incorporate new technologies. What is certain, however, is that computer-assisted language learning will continue to develop in the area of 
collaborative, socially-based language learning in its different modalities [9].

Presently, because of the wide scope of CALL, there are many present and future applications and technologies that are presently in the pipeline and will become more widespread in the future. For example, concordancers, programs that are used to linguistically analyze large bodies of text can determine word frequency, word use and the relative lexical value of a specific word whether it is a 'grammar word' with functional use or common lexical items such as common nouns, verbs, adjectives, etc. This tool can help advanced students gain metalinguistic awareness and improve skills as they gain greater proficiency.

Importantly, since the inception of virtual reality applications such as one, Distributed Interactive Virtual Environments, a pioneer virtual reality application (DIVE) developed by Carlsson and Hagsand [7], and immersive virtual worlds have become much more interactive and interesting to users all over the world in what is commonly called semi-immersive virtual reality or desktop virtual reality [20]. Future developments in CALL include virtual tutors that combine the presence of a VR avatar with the knowledge base of an expert system or the even more difficult applications that involve an expert presence.

While we wait for these applications, efforts are presently underway to better exploit existing technologies and available services. One important area of study is how to more effectively employ Web 2.0 technologies to language instruction and learning. This is a somewhat overlooked area of research because many professionals overlook that these social networking tools have been developed primarily so that native or near-native speakers can interact to achieve a specific goal, be it entertainment, work, etc. Social networking tools were not developed to help persons learn languages. However, they can be of significant value in that they provide support for language learners to interact with native speakers, although feedback or integration of these tools are not considered. Also, a great number of existing Web 2.0 tools, services and content [10] are freely available, which can perfectly support educational institutions facing worldwide increasingly budget cuts. In particular solutions based on existing Web 2.0 tools and open access might give developing countries affordable learning environments to cope better with societies expectations in our globalized world.

The literature shows that relatively little work has actually be done on how to modify or integrate different Web 2.0 applications to make them more effective for language instruction or language training. This situation has led us to initiate an international research collaboration between Graz University of Technology, Graz, Austria; Curtin University, Perth, Australia; and University of Colima, Colima, Mexico. The focus is on research and development of a flexible and affordable environment for foreign language learning and training.

This paper discusses our first research findings and reports on our first development results, which is an extended version of the ICL 2011 paper of Boruta, Gütl, Chang and Edwards in 2011 [6].

The remainder of the paper is organized as follows: Section II is given an historic overview of foreign language learning and discussed modern language learning and training support based on Web 2.0 and cloud ap- proaches. Findings lead to the requirements for a flexible and affordable learning environment which are outlined in Section III. Based on these requirements, the design and development of a first proof of concept is explained in Section IV and the usage viewpoint is given in Section $\mathrm{V}$. Lessons learned from the development but also from the application domain point of view are discussed in Section VI.

\section{LANGUAGE LERANING AND ICT SUPPORT}

There has been a long history on language education and research [49]. Foreign language or second language learning is one specific research field (see for example $[12,30,44])$ which is becoming increasingly important in our globalized world. The history of language learning began as the first tribes began to interact through conquest or trade. The early tools consisted of books, pens, pens, pencils, and blackboards as the goal was to translate or learn grammar in order to exercise the brain. This was the case because travel was still limited well into the $20^{\text {th }}$ century. In the second half of the aforementioned century, travel and business became increasingly simple as aviation and telecommunications advance. However, it was not until the last decade of the $20^{\text {th }}$ century, with the introduction of the Internet, that anybody with a computer and modem could communicate with persons in almost any part of the world. The first ten years of the $21^{\text {st }}$ century has expanded on the revolutionary web technology by introducing wireless communication, increasing bandwidth, streaming technologies, more powerful hardware and programming languages and applications, etc.

As a reaction to the increasing demand for worldwide communication (particularly, but not exclusively English) Computer-Assisted Language Learning (CALL) was born. Originally developed for mainfraims in the 1950s it can now be divided into three time periods, the 1950s to the late 1970s, the 1980s and the early 1990s, and the mid 1990s (WWW became public in 1993) to present. [5] Starting with the first period, CALL was highly influenced in the 1950s, 1960s and 1970s by behaviorism and the work of B.F. Skinner in [47]. In behaviorist theory, errors were considered things to be avoided, instead of opportunities to learn. Therefore, errors had to be eradicated. Pedagogically, this meant that students had to practice many rote exercises, memorize, and perform perfectly. Consequently, CALL software, still limited due to the technology of the times, focused on repetitive fillin-the-blank, multiple choice and simple writing programs. Computers were considered a perfect medium to teach languages because they never got tired of repeating, never got tired, and never lost patience with the students. During this time, the term programmed instruction was first used, which encouraged the use of teaching machines to individualize instruction and respond in a place where students could respond more comfortably without the affective "threat" of being wrong in front of peers [33]. What Skinner was proposing is the precursor to what today are called expert systems.

The second period started in the late 1970s saw a revolution with respect to language teaching methodologies. Two important proposals included Community Language Learning [15] and Total Physical Response [4]. Humanistic methods and techniques now saw language teaching as a human endeavor that was social in nature and should try to engage the entire person, including emotions and 
feelings. Methodologically, however, the most important contribution was Communicative Language Teaching (CLT). Stephen Krashen in 1981 [29], in his classic work, Second Language Acquisition and Second Language Leaning, made great contributions to how experts came to think about how languages are acquired or learned. This, in turn, supported pedagogues who supported communicative methods of instruction that were largely cognitivelybased and supported by social learning theory.

The revolution related to language learning methodologies of the late 1970's was paralleled by a similar computer revolution in the early and mid 1980's. For the first time, personal computers became available to the general public and schools could now purchase computers as they became smaller, more powerful, and more affordable. However, consumer versions of computers had so little processing ability that they proved to be of no practical use. This was even truer because there were virtually no software available for public purchase. This period, however, saw the publications of the first books on CALL which began to define what computers needed to do to be useful in the area of language instruction. [35]

The mid and late 1980s would witness an explosion of software, more developed programming tools, and more processing power. The 1980s consequently saw the advent of authoring programs that dealt with text manipulation and text construction, as well as more traditional exercises. However, authoring programs permitted teachers to add content that was specific to their classes, making the leaning experience more personalized and relevant. Software, furthermore, began to tackle lexical, grammatical, semantic, and logical problems presented in texts and even oral exercises were now possible due to expanded memory and the first codecs that compressed audio. This proved to be a great advantage as the programs became simpler to use and permitted the common teacher to participate in the edition process. [35]

The third period, starting in the 1990's were characterized by the more widespread use of CD-ROM technology which permitted the use of multimedia, thus drastically increasing interactivity by presenting lessons with different types of visual and auditory information, combined with more complex and more cognitively demanding activities. The major weakness of CD-ROM technology is that it is designed to be used in a standalone PC, which substantially decreases its value because it does not permit very much interaction with peers. Also there was not much flexibility in terms of customization or update of content according to the learning groups' needs. [35]

In the mid 1990s with the explosion of the Internet and the increasing usage of the World Wide Web (WWW) has raised the interest of Web-based learning applications. The first decade of the Web is also termed as Web 1.0 and can be categorized as mainly consumer based and passive. Consequently, learning applications was influenced in that way that they supported mainly teacher and content centered approaches, tough some synchronous and asynchronous collaboration as well as interaction and multimedia support has emerged. [10, 19] In this period of time, technology for language learning has been researched, developed and applied for skill building: (a) reading has been supported by Web-based delivery tools providing prepared content or selected content from external sources as well as annotations such as glossing formats, (b) writing has been enabled by synchronous and asynchronous applications, (c) listening by multi-media tools providing prepared content or selected content from external sources as well as text-to-speech technologies, and (d) speaking by speech-to-text and analysis tools as well as communication tools. As (e) assessment and feedback has to be seen as integrated part of the learning process, also tools for these purposes have become increasingly prominent and available. In an orthogonal way, what we want to term auxiliary tools have emerged such as dictionaries, thesauri, spell and grammar checker, style checker, and translation services. Also, specific tools that support collaborative language learning, life-long and selfguided learning, cultural context, and specific settings and contexts. [23, 41] As a specific strand of intelligent tutoring tools, Intelligent Computer-Assisted Language Learning (ICALL) has been evolved over the last three decades. Like in intelligent tutoring systems, the idea is to have personalized learning experiences and guidance with personalized feedback. In general to idea is to support language learners in all the above outlined activities, thus technologies include natural language processing, speech recognition, automatic assessment and feedback provision. Tough technologies and computation capacities have been improved significantly, there is still much room for research and improvements. [1]

At the beginning of the $21^{\text {st }}$ century, there was a transition from the Web 1.0 era towards the Web 2.0 are. The Web 2.0 notion is more than just the enhanced Web 1.0 and includes “(1) social phenomena such as the Web for participation, (2) technology for significant change in web usage, and (3) design guidelines for loosely coupled services" [46]. From the usage point of view, this transition enabled user much easier to publish and share content, communicate and socialize. From the technical point of view, Web 2.0 enabled dynamic content section and enhanced user interfaces. A variety of tools become available and attractive for the users, such as blocks, wikis, video blogs, tagging and content sharing of various media, and social networks and platforms [24]. Consequently, as educational settings and approaches have a long tradition in adopting new technologies, the Web 2.0 has lead researchers, educators and practitioners to move towards E-learning 2.0. We see the E-learning 1.0 as mainly content-centered, centralized and static, which in E-Learning 2.0 has moved towards a learner-communitycentered, decentralized and dynamic learning environment. [19, 46]

It is obvious, that CALL and ICALL have also been influenced by and build on Web 2.0 and E-learning 2.0 concepts and technologies. In order to illustrate the great variety of research and application of such technologies, some selected examples are briefly given in this paragraph. The author in [34] reports on the application of blocks (personal block, class block and project block) to support autonomous second language learning and to develop intercultural competence. The authors in [43] report on an experimentation applying a wiki system to extend student's language learning experiences beyond classroom. Facebook as a social software tools has been applied by [28] to support second language learning activities, namely to improve language skills (writing and communication skills), confidence and motivation. As an example of using multi-media and modern content sharing tools, the authors in [22] using YouTube and Edublogs to cover an simple experiment in students' specific main 
PAPER

FLEXIBLE AND AFFORDABLE ForEIGN LANGUAGE LEARNING ENVIRONMENT BASED ON WEB 2.0 TECHNOLOGIES

subject field by doing a background research, administer the experiment, documenting the results and present the results their class maids.

Within the last couple years, cloud computing has become one of the promising technologies and business models [14]. Especially Software-as-a-Service (SaaS), which are WAN-enabled applications to be outsourced and accessible form the Internet, can also offer support CALL and ICALL settings.

On a more general viewpoint, first and second language education can be supported by a great variety of modern technologies and a myriad of tools and services. Language learning support of reading, writing, listening and speaking is supported by online accessible and usable systems, which includes content creation, sharing, search and recommendation, asynchronous and synchronous communication. Language specific tools and technologies such as dictionaries, thesauri, spell and grammar checking, style checking, natural language processing as well as speech-to-text and text-to-speech technologies. [1, 22, 23, 28, 34, 41, 43] Also assessment and feedback tools for self, tutor and peer assessment are available and even automatic approaches for test item creation and assessment is an active research field [18, 21].

There is no doubt, there is a huge number of services and content available to support language learning activities and settings, however, these services are almost isolated silos. Modern e-education requires a great flexibility in term of selection of tools and their combination related to a number of characteristics, such as the needs of the learner community, the learning objectives and the underpinning pedagogy [19]. This is in line with the emphasized need of sound pedagogical and language learning theories as well as design principles by a number of researchers in the CALL domain [41]. This situation led us to initiate research on the flexible combination of services for language learning support.

\section{REQUIREMENTS FOR A FLEXIBLE AND AFFORDABLE LEARNING ENVIRONMENT}

Requirements can be separated into two parts: firstly in general requirements for a modern e-education system based on Web 2.0 tools or more specifically based on elearning 2.0 approaches. This requirements have been discussed elsewhere, such as in Gütl and Chang [19] and Chang and Gütl [10]. The application domain requirements are following the design guidelines for computerbased second language learning by Hemard in 1997 [25], who has proposed the following seven design criteria: "(1) making key linguistic characteristics salient, (2) offering modifications of linguistic input, (3) providing opportunities for 'comprehensible output,' (4) providing opportunities for learners to notice their errors, (5) providing opportunities for learners to correct their linguistic output, (6) supporting modified interaction between the learner and the computer, and (7) acting as a participant in L2 tasks" (Hemard, 1997 cited in [41]).

Based on the Web 2.0 and language specific needs stated above and related work which highlighted gaps and identified improvements in existing tools, both functional and non-functional requirements on an abstract level are outlined as guiding tool for the proof of concept described in the following section.

\section{Functional requirements:}

- enable synchronous collaboration and communication (share documents and images, real-time collaborative writing, chat)

- enable asynchronous collaboration and communication (mail and mailing lists, forum, wiki, document and image repositories)

- support user customization (personalize personal pages)

- enable group coordination (calendar, polls)

- support media types (documents, images, videos)

- provide language-specific tools (dictionary, spell checker, text to speech converter, translator)

- support assessment, feedback and monitoring (evaluation/rating mechanisms, feedback, monitor user activity)

- offer resources for learning/practicing English (links to language learning sites, reading, writing, oral and reading comprehension, grammar, spelling, pronunciation, etc.)

Non-functional requirements:

- offer a low-cost solution (combination of opensource and free technologies, incorporation of existing services and web-accessible tools)

- are easy to set up and easy to use

- provide scale and reliability

- aim to be adaptable to different learning methodologies (offer flexibility to certain users, single sign-on)

\section{Design And DeVelopment of A First ProOf OF CONCEPT}

In order to move towards a flexible and affordable foreign language learning environment which makes use of Web 2.0 technologies, we have decided to implement a first proof of concepts focusing on selected aspects of the entire set of requirements outlined before. This was motivated by the interest on how various Web 2.0 tools, existing services and content appropriate for language training can be combined and used in a seamless in a learning environment. Thus, the focus for the proof of concept is on the following aspects: (1) provide open and closed learning environments for formal and informal learning groups and activities, (2) provide flexibility in terms of usage and combination of general learning and language learning tools and content, (3) make use of Web 2.0 learning approaches, and (4) build on open and free tools as well as an affordable way to run the system even for institutions in developing countries.

As underpinning platform for integrating and seamless combining Web 2.0 tools and services, two different approaches have been identified: firstly, platforms in the cloud, such as Google sites and apps [16] or Amazon Web services [2]. Secondly, platforms which are run by the individual institutions, such as Liferay Portal [36] or the platform developed by the ROLE project [45]. In order to keep independent of commercial decisions of companies and have full control on features and functionally, cloud approaches have not been further taken into account. There is also a great variety of open platforms to be run by individual institutions and potentially applicable for building an appropriate learning platform. A further 
PAPER

FleXiBle AND AfFordable Foreign LANGUAGE LEARning ENVIRONMENT BASED ON Web 2.0 TECHNOLOGIES

investigation would be necessary to evaluate the different platforms, however, this is beyond the scope of this paper. Finally, we have decided to use the Liferay portal as the group had already had experiences on the platform and stable versions and a number of tools and plugins are available.

\section{A. The Underpinning Platform Liferay at a Glance}

For the proof of concept described in this paper, implementation has been built on Liferay Version 6, see also [39].

Liferay Portal is built on Java and Web 2.0 technologies. Its functionality support content management and Web publishing; it covers collaboration aspects such as blogs, wikis, message boards and social bookmarking; and the portal also social networking features such as friend feeds and activity feeds. The Liferay Portal can be easily customized by a theme and template mechanism and highly flexible configuration of tools and combination of tools. A service-oriented architecture supports developers to develop new or reuse and composite services.

From an architectural point of view, the Liferay system consists of two major parts: (1) the Portal Core which provides the core infrastructure and manages instances of the second major part, (2) the individual plug-ins.

The Liferay portal version 6 and above, see also [53] supports the following types of plug-ins or extensions: (a) Hook Plugins are components which are deeply integrated in the core functionality and enables developers to override or replace functionality on the event system, the model listeners, portal properties and even core Java server pages. (b) Portlets which are a sort of web applications being a portion of a Web page. Liferay provides the portlet continer and supports Portlet version 2.0 standard and is backword compatible with Portlet version 1.0 standard. Portal applications can be realized by aggregated portlets implementing small amounts of functionality or implementing a complex application within one Portlet window. The Portlet approach does not only support Javabased programs but can also consume Portlets implemented in other languages such as PHP, Ruby and Groovy. (c) Themes are used to adapt the look and feel of the portal across all Web sites and applications. This plugin type can be deployed at running systems and changes are effected immediately. (d) Layout Templates are the portal solutions to arrange the portlets on the page. In addition to that, specific portlets can be installed to make use of (e) Gadgets and Widgets (see [37]) which are loosely integrated small programs and services form other Web sites, and (f) I-Frames (see [38]) which enable developers to loosely integrate Web pages from other sites.

Liferay makes use of an advanced roles and rights concept (see also [6]). The portal is accessible by users, which can be clustered into user groups and can be assigned with different roles in different contexts, namely in organizations and communities. Organizations are hierarchical collections of users that show where a user belongs in a particular hierarchy or organizational unit. Communities are collections of users who have common interests and they can be open, restricted or hidden in relation to the access authorization of a user. Teams are groups of users for specific functions within a community or organization. A user represents the physical user of the portal, who has an account that the user employs to log in to the portal and it offers the user a specific set of personal pages within the portal. Pages belong to a user, a community or an organization and can be public or private. Public pages are accessible to anyone and private pages are only accessible to the users who belong to an organization or a community to which the pages belong. The content of personal pages, communities and organizations can be pre-defined using site templates. Roles are used to define permissions across the portal, across an organization or a community. Therefore portal roles, organization roles and community roles are available, which define the scope of a role. Roles are used for portal security and define which resources a specific users can access.

\section{B. Design and Development Aspects}

The proof of concept has been based on Liferay Community Edition 6.0.6 which is bundled with the Apache Tomcat 6.0.29 [3, 51] as the application server and MySQL database 5.1.49-1ubuntu8.1 [42] and has been deployed under Linux distribution Ubuntu 10.10, 64bit [52]. In order to keep the effort as low as possible and to have a first version for evaluation ready very soon, a reuse-based software engineering approach [48] has been applied. This software engineering approach is characterized that base on the initial list of requirements the fittest components and libraries are selected, and in a second step the requirements are reconsidered accordingly to keep the effort low, and finally some of the components are adopted or newly implemented. To make use of the variety of different available tools, services and content, the system has been designed in a very flexible and open way. Figure 1 shows the conceptual architecture. The Foreign Language Learning Environment is built on top of the Liferay Core and makes use of Liferay specific functionality but also make extensive use of cloud services and content in the cloud. To this end, some of the plug-in mechanism of the system are used, namely the layout templates, hook plug-ins as well as a range of portlets including specific portlets to enable the integration of widgets and gadgets as well as the integration of content and services using the i-frame technology (see also Boruta et al. in [6]). As a concrete sample scenario, the support of learning English as foreign language has been targeted, as this scenario is widely used and also a great number of tools, services and content are available.

A great portion of the learning environment's basic functionality was covered by selected out-of-the-box portlets of the Liferay portal. Thus, the basic management and navigation is provided by the standard portlets, such as web content, asset publishing, document and image management, document library manager, image gallery, breadcrumbs, nested portlets, site map,and user directory. Some of the communication and collaboration features have been covered by page ratings, calendar, chat, mail, message boards and wiki portlets. Additionally, the search and invite friends portlets have been adopted to be compatible with Liferay Community Edition 6.0.6

As a second valuable source the Liferays' community plug-ins [36] has been identified, which is an online repository of files and add-ons to the core Liferay technology contributed by the Liferay community. For advanced communication and collaboration features, the following unchanged portlets developed by the community has been added: list portlet for managing group work, group notification portlet for sending e-mails to commu- 
PAPER

FleXible AND AfFordable Foreign LANGUAGE LEARning ENVIRONMENT BASED ON Web 2.0 TECHNOLOGIES

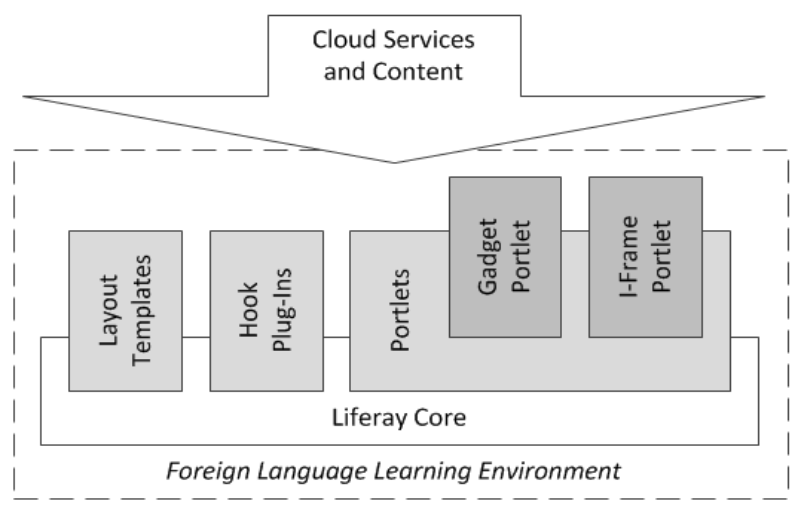

Figure 1. Conceptual Architecture of the foreign language learning environment.

nity members. To redirect a user after successful login to a predefined landing page (private homepages), the login landingpage hook has been added as well. Also, the display video portlet has been adjusted according specific requirements to render videos from Youtube, Vimeo, DailyMotion, Revver and SevenLoad.

In order to further enrich the learning platform with domain specific functionalities and features for foreign language learning, different types of Liferay plug-ins have been developed or services have been added to the core learning environment (see also [6]). Cambridge's Doubleclick dictionary search has been implemented as an example as a language learning specific Liferay portlet plug-in. Furthermore, a protolife hook for overwriting some core functionality and selected pre-existing portlets has been implemented. This includes the display of the directory portlet, user details portlet and the form of the login portlet, as well as the behavior that resembles access to the control panel by a user. Further existing widgets or gadgets have been integrated by using the OpenSocial Gadget: Cambridge Online Dictionary [11], Google Translate Gadget [17], Lab Pixies TODO lists and Lab Pixies Translate [31]. Finally, the Lingro Dictionary [40], a spell checker [27], text-to-speech functionality [50], Collins dictionary and thesaurus [13] and Cambridge vocabulary trainer [8] were embedded in the portal using the iFrame portlet.

\section{THE FOREIGN LANGUAGE LEARNING}

ENVIRONMENT FROM THE USAGE POINT OF VIEW

As our proof of concept has been designed to support highest flexibility in terms of tools and cloud services to be used but also in terms of learning tools for concrete learning activities, we have decided to focus on three different scenarios which require different organizational aspects and tools to be applied (see also [6]). These three scenarios support English language learning as foreign language for (a) an open learning community, (b) closed and formal classroom-like learning communities, and for (c) self-organized learning groups, which will be explained in this section.

Built-in rights and role management of Liferay (user groups, roles and communities) are used to organize the elearning environment for the three aforementioned scenarios. The language training environment is organized in different views or pages providing several selected portlets. All sets of pages within the portal are divided into two types of pages: public and private pages. Public pages are accessible to everyone. Private pages are only accessible by a user if the pages belong to the set of private pages of a user or the user is member of a community to which the private pages belong. According to user roles, a high flexibility in terms of tool, layout and content management can be granted.

Five different types of users are managed within the learning environment: (1) the 'teacher' who has assigned the portal role 'User' and the community role 'Classroom_Teacher' with extended rights to manage communities; (2) the 'student or learner', who has just the portal role 'User' and can be assigned to one or more communities by the community roles, some of them even can granted with extended rights to manage communities; (3) the 'technically more skilled teacher' who is assigned to the portal role 'Teacher_Admin' which gives that user the ability to create and manage communities within the leraning environment; (4) the 'community manager', who has the portal role 'Community_Manager', which gives the user the right to create and manage communities within the portal as well; and (5) the 'administrator', who can configure portal resources, manage templates and can assign users with the designated role. Normal users, 'students and learners' do not have access to the portal's control panel.

The administrator role can set the global server settings. A control panel is used for the administrative tasks (see also Figure 2), like administer users, create portal structure or implement security. When using the Control Panel an administrator is able to make changes to the administrator's account, add/modify/delete Users, Communities, User Groups, Roles, Password Policies, Site Templates, manage portlets and much more.

The portal role 'Classroom_Teacher' defines extended permissions, e.g. such users can organize content in restricted areas, configure views and selected portlets. Figure 3 outlines a selected teacher view managing the layout and usage of portlets within a community. This portal role has the privileges to organize the structure of the community site and controls the tools (portlets) to be used and the layout or pages. The portal role 'Teacher_Admin' allows a user to create, manage and even delete certain communities within the learning environment. The user is able create a community, name it, choose a type (open, restricted, private), select a site template and manage the community pages. Which includes, that the user is able to reorganize the community pages and even add further applications, e.g. iFrame portlets or the double-click dictionary portlet and much more. The user is allowed to assign new members to the community, when the community is restricted, but not to assign new members with certain roles.

The portal role 'User' is the default role that has the permission to see all content in the portal and communities the user is a member of. In some restricted areas of community portal users are granted privileges to add and edit content. In order to enable users to initiate and organize learning communities, the specific user role 'Community_Manager' must be assigned. This roles grants users such privileges to manage self-organized learning groups.

In order to keep the administration effort to a minimum and the access barrier for potential users low, a selfregistration procedure is offered by the portal. After a user creates successfully an account, the set of pages of the user group site template is copied to the personal pages of 
PAPER

FleXible AND AfFordable Foreign LANGUAGE LEARning ENVIRONMENT BASED ON Web 2.0 TECHNOLOGIES

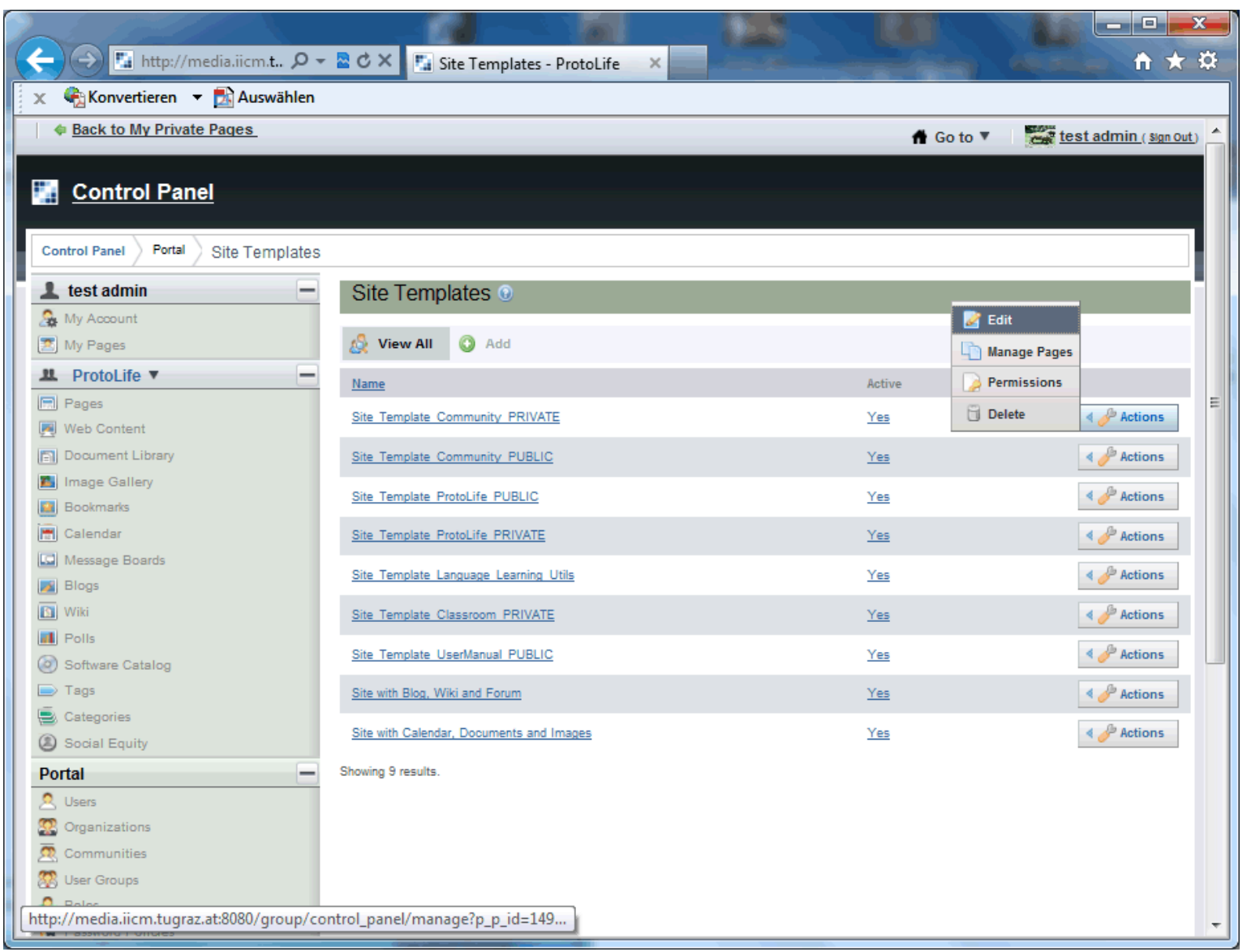

Figure 2. Administration Panel enables users with administrator privileges to control the Liferay portal; exemplarily site template administration is selected to preconfigure page layout and settings used in the learning platform.

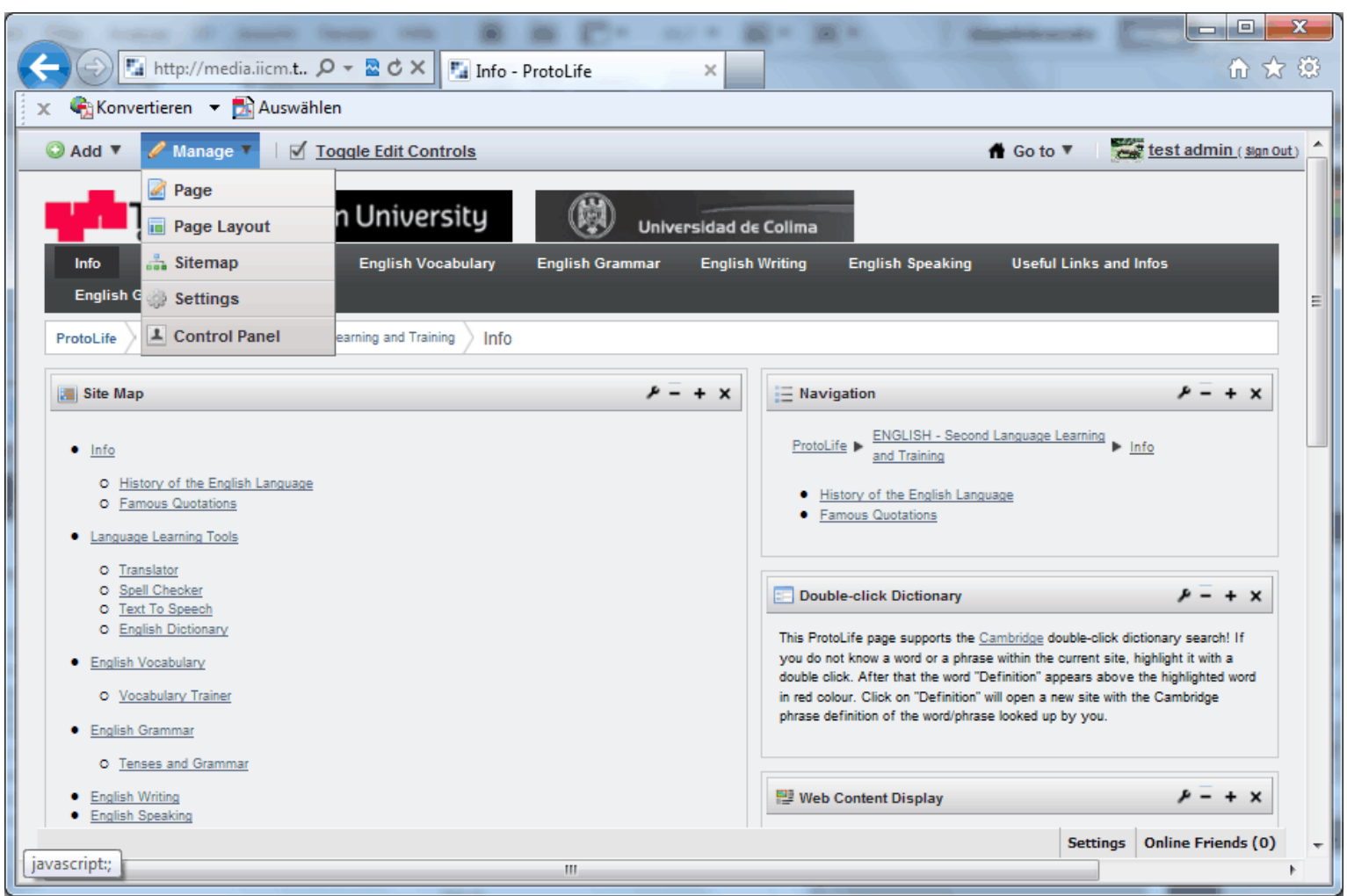

Figure 3. Users' granted with proper privileges can make use of great flexibility to add and edit pages as well as page layout and the integration and configuration of portlets. 
PAPER

FLEXIBLE AND AFFORDABLE ForEIGN LANGUAGE LEARNING ENVIRONMENT BASED ON WEB 2.0 TECHNOLOGIES

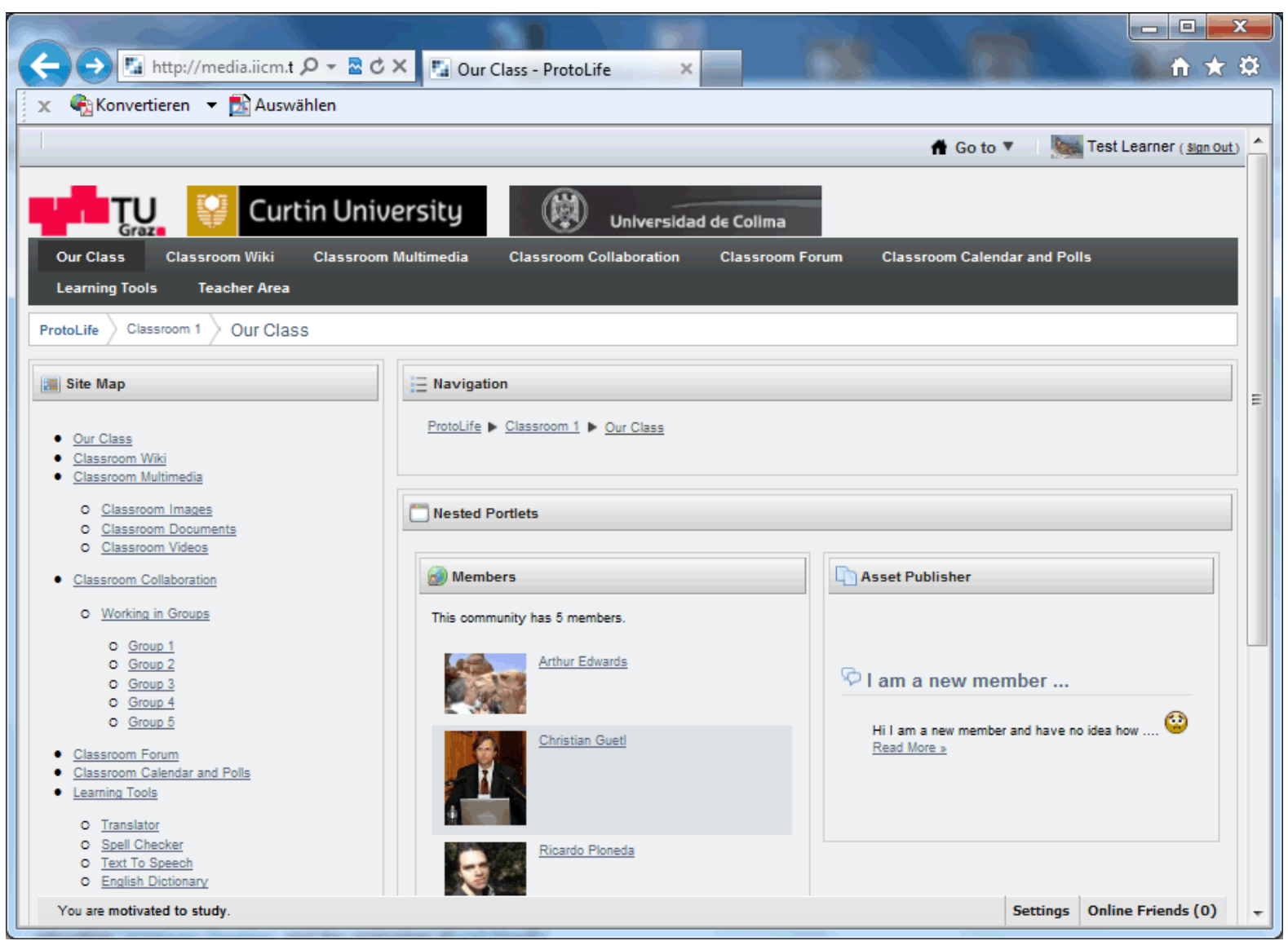

Figure 4. Selected example of a learning group with shared content and individual group working space.

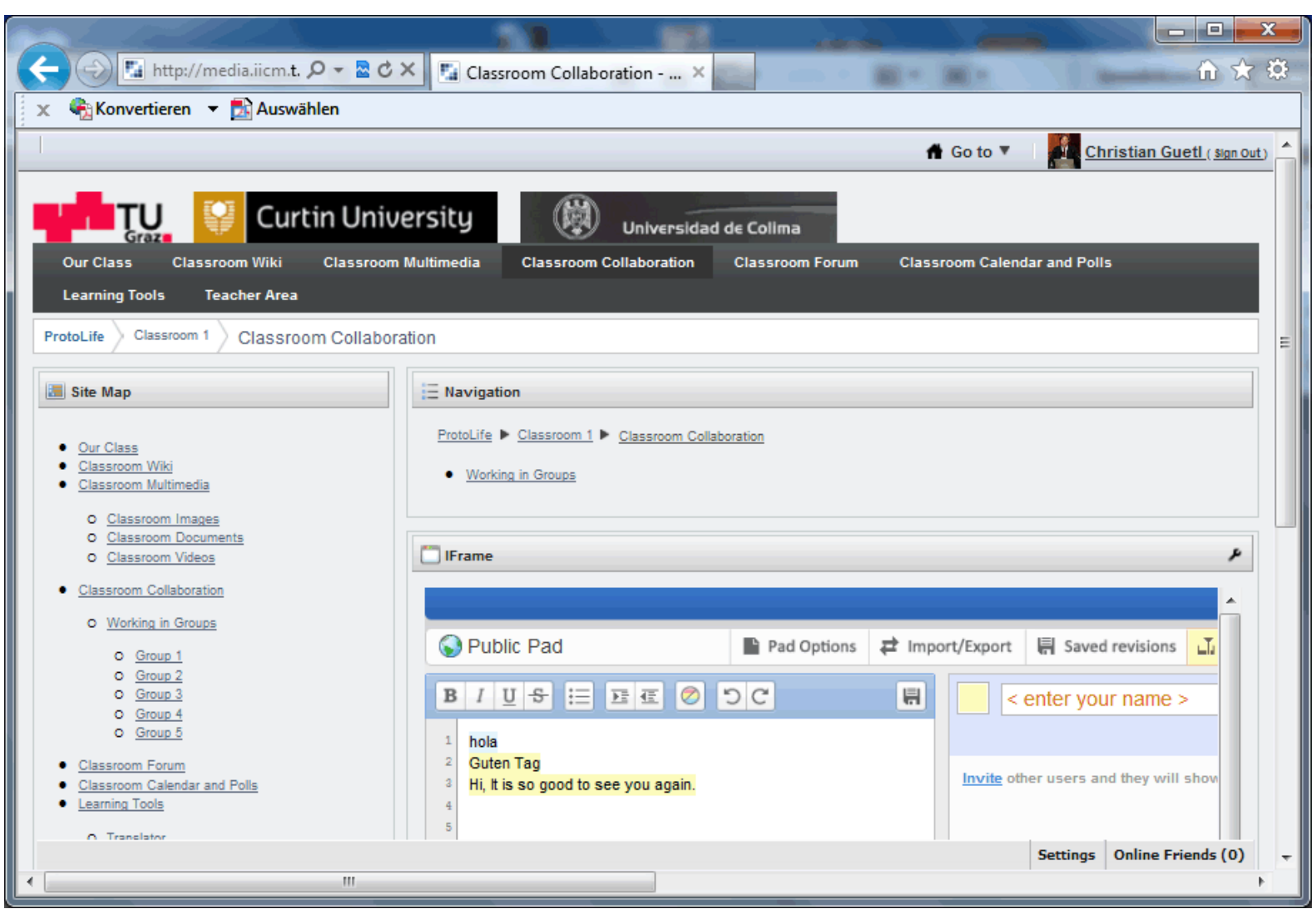

Figure 5. Callaborative writing tool using an existing service in the cloud. 
PAPER

FLEXIBLE AND AFFORDABLE ForEIGN LANGUAGE LEARNING ENVIRONMENT BASED ON WEB 2.0 TECHNOLOGIES

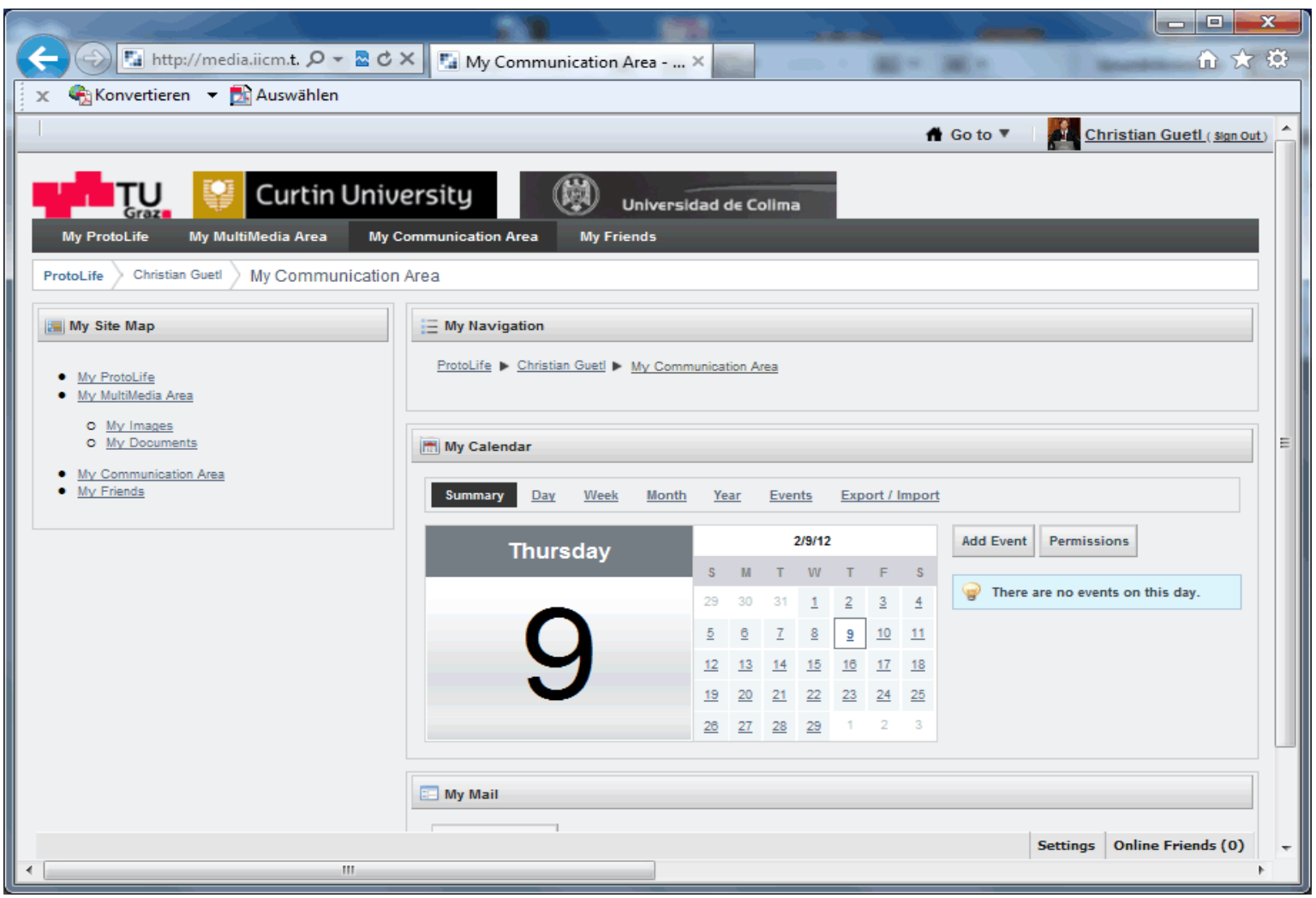

Figure 6. Calendar protlet as selected example of group coordination and communication tools.

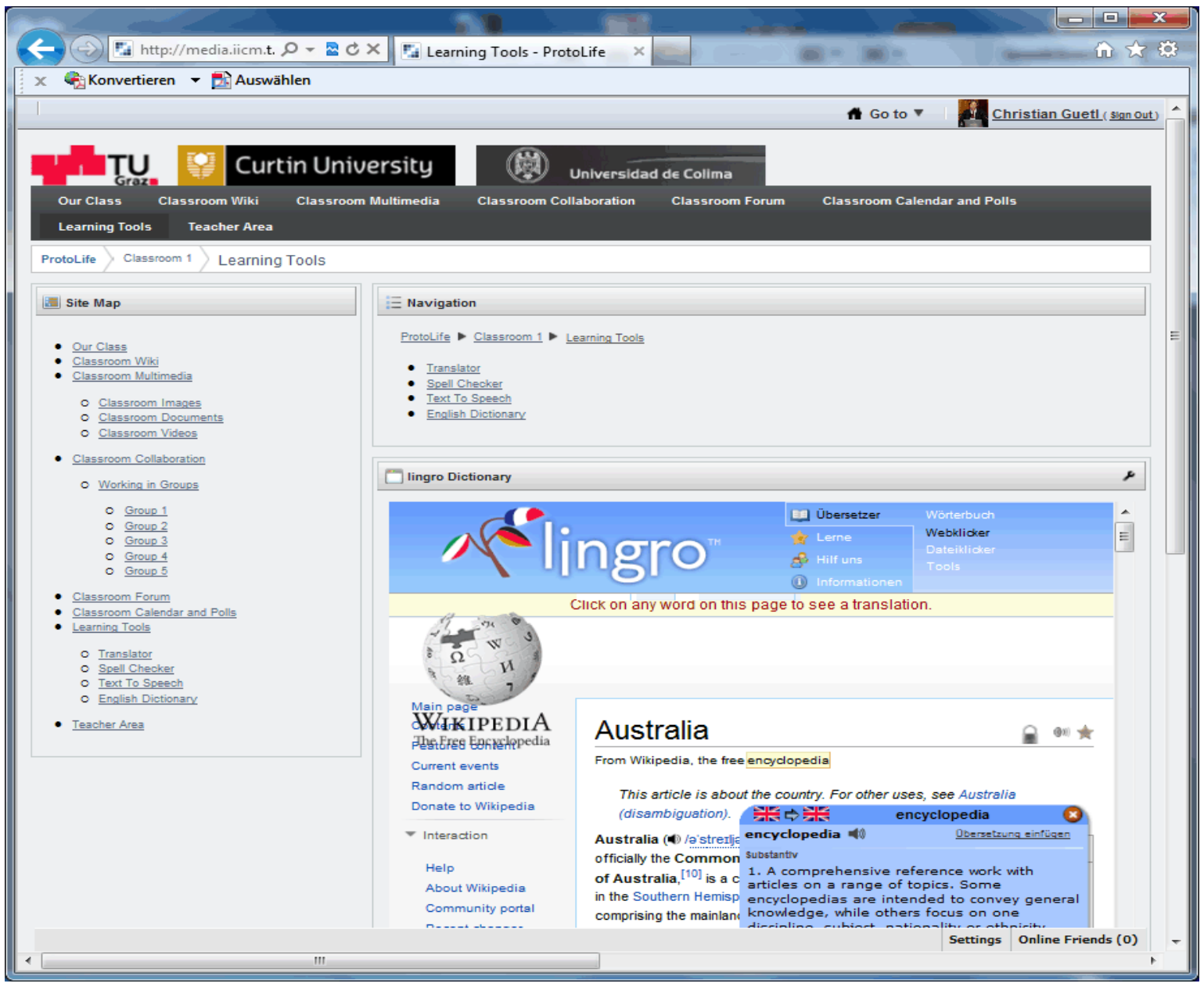

Figure 7. Dictionary cloud service for cloud content as selected example of specific language learning tools. 
PAPER

FLEXIBLE AND AFFORDABLE ForEIGN LANGUAGE LEARNING ENVIRONMENT BASED ON WEB 2.0 TECHNOLOGIES

the user to provide a pre-configured view and initial content. After logging into the system, the default is that users are redirected to the users' personal pages. However, users can enroll freely open to join community sites or can request for closed communities to get accepted members.

Focusing firstly on the closed learning communities, the supported learning scenario classroom community is pretty much comparable with a formal language learning class in school or a course at a university. Such a class is managed by one or several teachers and has a group of students. Consequently, there can exist one or more users assigned the teacher role and students, who just have the portal role 'User'; all of them are assigned to the specific community role or, more specifically, to the class community role. It is also worth to mentioning that a user can be a teacher in one community and a normal learner in another community. Just with the portal role 'Teacher_Admin' an user is allowed to configure and manage pages and communities portal-wide.

In our first implementation such class communities must be created and set-up by an administrator. A classroom is a restricted community and has only private pages, thus only members of the classroom can view content and use services.

At the creation time of the class community, the site template is copied and provides predefined page structure, content and portlets to all members of the classroom community. Figure 4 gives an illustrative example of the entry page of such a learning community and the content structure and tools offered. Figure 5 shows exemplarily a collaborative writing tool as one of the integrated cloud tools of the language learning portal and Figure 6 shows the group calendar as one example of the group coordination and communication tools. In general such learning communities includes a classroom wiki; a web page for multimedia content, where students can view and download images, documents and videos provided by the teacher; a separate page for real-time collaboration and group work using a TitanPad; a forum; calendar and polls. Specific learning tools offering translator, spell-checker, text-to-speech and dictionary to the classroom members (see also Figure 7). Additional, members assigned to the teacher role have permission to access the 'Teacher Area'. This area enables teachers to organize the learning content and student assignments, to send mails using a mailing list and monitor the activities of students. For group work, groups can be defined and group communication will be supported.

In a similar way, self-organized group learning can be initiated and managed by portal users which have been granted extended rights on the portal by assigning them the role 'Community_Manager'. In this use case, a group of users of the portal can form a learning group community. For such communities the system provides a learning environment similar to the classroom community setting but enables the members of the group to configure partly portlets according to their needs and to organize content on their own. ProtoLife offers those informal learning groups also various social network features that are similar to other social networks. The e-learning prototype makes use of functionalities to find, organize, communicate and collaborate with friends and peers in the context of language learning.
As one example of on open and freely accessible learning group, every user is per default also assigned to the open community 'ENGLISH - Second Language Learning and Training'. This language learning community supporting various English learning and training activities but also space for communication and social interaction. It offers language learning widgets, such as a translator, spell-checker, text to speech converter, English dictionary, information and exercises according to English vocabulary, grammar writing and speaking, many useful links are presented and appropriate to the conceptual idea behind game-based learning, it offers some English games depending on the learners' capacity.

\section{LESSONS LEARNED}

This section is organized into two parts: firstly, findings on the viewpoints of the development are outlined; and secondly, aspects and insight from the application domain of foreign language learning are discussed.

\section{A. Technological and Development Aspects}

To start with the underpinning platform, Liferay has been proofed a very powerful system. It supports high flexibility in terms of a sound plug-in system. Developers can make use of adding and changing (overwriting) existing functionality. Even without any implementation effort, a great variety of existing tools (portlets) available from the Lifery platform but also from the Lifery community enables developers to build powerful learning systems, event for learning purposes. There are also helpful documentations and forums, but a minimum of technical expertise is required. Some of the portlets are error prone and do not render always the expected functionality and behavior. Some of the portlets have been adapted in order to meet the specified features which required software skills.

The Liferay portal has a very sound concept to structure and manage portal users and access rights. It has proven highest flexibility and enables by means of organizing roles, teams and communities to establish a very finegrained rights system for managing content, layout and tools, and members of learning groups. However, the concept requires a good understanding and needs skilled users to configure and administer the portal. Simple users just committed to managing a learning group might not have the necessary computer literacy and simplified tools might be necessary for a wider usage in foreign language training.

The Liferay portal supports also our called idea of highest flexibility to select learning tools and configure learning spaces. A sophisticated template and page layout mechanism paired with the configuration of tools to be used and content to be flexible structures enables portal users with appropriate privileges to manage learning communities according to specific needs. Again, appropriate skills and computer literacy would be required. A set of predefined learning environments for different purposes to select from and easy ways to adapt to specific needs accordingly might further support the language learning community.

In terms of flexibility of selecting and using different tools and make use of existing services and content, Liferay not only support the flexible arrangement and configuration of portlets, but also allows to integrate 
PAPER

FLEXIBLE AND AFFordable Foreign LANGUAGE LEARNing ENVIRONMENT BASEd ON Web 2.0 TECHNOLOGIES

widgets and gadget as well as services and content using the i-frame concept. All in all, it turns out on the positive side that selecting and even combining tools and services is of great value to choose specific tools for specific learning activities and learning groups. On the negative side, all those tools provide functionality mostly in a closed way and do not all users to combine different tools and content in a seamless way in a broader scale. To illustrate this, the platform perfectly supports users selecting a Wiki system and a spell checker and dictionary service of the learners' group choice, but it is not possible to tightly integrate the language learning support tools in the Wiki system without any extra effort. Also, at this stage, a simple mechanism is missing to enable or disable the language learning support tools according the learning task from case to case.

Further investigations and research needs to be done to how the learning community in general and the language learning community specifically can make use of preexisting tools and services in the cloud to be used in a seamless way by orchestrating them in a simple way by the users of the learning community. Some preliminary research on the level of technology infrastructure has been reported elsewhere in [32]. Also, related to that is the management of accounts of different services but also privacy and security aspects, which also needs further attention and research.

\section{B. Application Domain Aspects}

From the general users' viewpoint in learning application, the great flexibility as well as the broad spectrum of usable services and tools can be reported as the main advantages. On the negative side the users must cope with a number of partly unfamiliar tools and deal with a high complexity. To allay this issue, the platform includes a site map and a breadcrumb portlet to make the navigation for the user easier and to make it unlikely that a user get lost within the portal. Also, information accessible on the welcome page, including a wiki that provides information about the basic functionalities of the prototype, FAQs and the intuitive layout of the web site, support users using this prototype after only a short self-study period. Because teachers have extended rights and need to configure some portlets, a special how-to manual is available for users with information regarding their role and privileges. The administration of the prototype by using the control panel is a comfortable solution, however, creating new communities and managing users requires more effort.

More specifically, the learner's viewpoint on the foreign learning platform is discussed within the remainder of this section. Teachers felt that the platform layout is typical for social media applications. This is an advantage because it adds intuitiveness to the application as its users have already seen applications that are similar. The ability to register and add personal information is almost exactly as students have come to expect from having used Facebook or similar social media tools. Teachers are able to assign students to groups once they have signed in is simple and quick, as are most of the processes involved in group administration. What is most impressive, however, is the variety of application and tools. Teachers found these to be very interesting and appreciated the fact that they were all in the same platform, permitting teachers to use them without having to go to different sites. The teachers interviewed commented that a great number of sites needed to be added; however, they understood it was only a prototype. The teachers liked the links to the dictionaries, especially Cambridge Dictionary, because if pronounced the words for the students. The teachers found the Wiki exciting but had difficulties using it. The similar was true for the discussion forum. They understood the concept and reason for their being. They even knew how they might use these tools, they just did not know the mechanics, meaning that some teacher training is necessary. The teachers were particularly excited about the Titan Pad application. Synchronous collaborative writing is a very exciting topic and to be able to have a history of the interaction allows for error analysis and the study of group interaction as part of the evaluation. They also liked the spell checker because students could check their work before posting without having to leave Protolife.

Teachers, however, had some observations as well as things they did not like. The translator feature did not function in the expected way. They felt the translator function was very important but needed to be turned on or off, according to the specific needs of the situation. They did not like the text to voice application at all. The voice was mechanical, read to fast, and not easily understandable. A change to another, more lifelike voice is necessary; maybe even a commercial application. The teachers most importantly commented that although almost all tools were incorporated, that they would like to see a Blog--a teacher and a classroom blog, however, this could be easily fixed as Liferay offers this tool as well but it would need to be configured. Finally, they commented that using frames took away the feeling of true integration and that they wish for an application that was seamless and permitted the transference of information from one application within Protolife to another without having to move through frames to eventually cut and paste data. One of the first lessons learned from the teacher review is, that some more Web 2.0 experienced teachers are more comfortable with the high flexibility and features to configure and compile a specific learning environment. Computer inexperienced teachers are not able to configure their learning environment and found all tools they would need for their learning-teaching activities. These findings reveal that a number of predefined learning environments suitable for different settings should be offered and should also be easy to adapt to specific needs. Also first experiences call for an easy way to enable or disable specific tools according to learning activities, such as getting the support of a spell checker or not according to the learning and teaching objectives. Also it has been found that appropriate assessment and feedback tools both for teachers and peer are required but not integrated in this first solution.

\section{SUMMARY AND FUTURE WORK}

Competing in a globalized world requires strong foreign language skills which must go far beyond traditional foreign language learning in current formal and informal settings. Modern language teaching and learning environments are increasingly employing technology. Computerbased language learning has been an active research and development field but also has been applied in learning settings for decades. The transition towards Web 2.0 technology and services as well as the broader availability of Software-as-a- Services within recent years provides useful services for langue learning settings. The support 
includes activities of reading, writing, speaking and listening, but also assessment and feedback as well as language specific services such as dictionaries and thesauri. The main issue in this context is that these services are almost isolated silos. Modern e-education requires a great flexibility in term of selection of tools and their combination related to a number of characteristics, such as the needs of the learner community, the learning objectives and the underpinning pedagogy. This situation calls for a flexible selection and combination of services for language learning support.

In order to moving towards a flexible and affordable foreign language learning environment which makes use of Web 2.0 technologies, we have decided implementing a first proof of concepts to investigate on how various Web 2.0 tools, existing services and content appropriate for language training can be combined and used in a seamless in a learning environment. Thus, the focus for the proof of concept is on the following aspects: (1) provide open and closed learning environments for formal and informal learning groups and activities, (2) provide flexibility in terms of usage and combination of general learning and language learning tools and content, (3) make use of Web 2.0 learning approaches, and (4) build on open and free tools as well as an affordable way to run the system even for institutions in developing countries. For the proof of concept described in this paper, implementation has been built on Liferay version 6 .

In order to show and evaluate the flexibility and applicability of our solution, three scenarios has been selected supporting English language learning as foreign language: (a) an open learning community, (b) closed and formal classroom-like learning communities, and for (c) selforganized learning groups.

The findings, both from the technical and usage point of view, are promising. Available Web 2.0 tools can be selected and combined in a flexible way to support the variety of learning activities and learning settings. However, findings from our first approach and preliminary evaluation also revealed much room for improvements. On the technological side, the first approach has not sufficiently solved the requirement of a seamless integration of tools and services. Form the pedagogical and usage point of view, the proof of concept has not covered well the assessment and feedback aspects as well as more support in preconfiguring of learning settings and tool support must be considered in future work. We also plan to experiment our solution in different practical language learning settings.

\section{ACKNOWLEDGMENT}

This paper is part of research resulting of visiting academic activities of Stefanie Boruta and Christian Gütl at the School of Information Systems. The visits were supported and sponsored by School of Information Systems and Curtin Business School, Curtin University, and Institute for Information Systems and Computer Media (IICM) at Graz University of Technology

\section{REFERENCES}

[1] Amaral, L., Meurers, D. (2011). On using intelligent computerassisted language learning in real-life foreign language teaching and learning. ReCALL, 23, 1, 4-24. http://dx.doi.org/10.1017/ $\underline{\text { S0958344010000261 }}$
[2] Amazon Web Service (2012). Amazon Web Service. Last retrieved Feb. $9^{\text {th }}, 2012$ from http://aws.amazon.com/de/

[3] APACHE (2012). Apache HTTP Server. Apache Software Foundation, last retrieved Feb. $11^{\text {th }}, 2012$ from http://projects.apache.org/projects/http_server.html

[4] Asher J. (1977). Learning Another Language Through Actions: The CompleteTeacher's Guidebook. Los Gatos, Calif.: Sky Oaks Productions.

[5] Beatty, K. (2003). Teaching and Researching Computer Assisted Language Learning. New York: Longman.

[6] Boruta, S., Gütl, C., Chang, V., \& Edwards, A. (2011). Foreign Language Learning Environment built on Web 2.0 Technologies. International Conference on Interactive Computer-Aided Learning, ICL2011, Sept. 2011, Piestany, Slovakia, pp. 82 - 88.

[7] Carlsson, C., \& Hagsand., D. (1993). DIVE - Multi-User Virtual Reality System. VRAIS '93, IEEE Virtual Reality Annual international Symposium, Pp 394-400. http://dx.doi.org/10.1109/ VRAIS.1993.380753

[8] Cambridge (2011). Vocabulary trainer. Last retrieved July $28^{\text {th }}$, 2011 from http://www.lingoclub.com/html2/index.php?option= com.

[9] Chapelle, C. (2003). English Language Learning and Technology. Oxford: Oxford University Press.

[10] Chang, V., \& Gütl, C. (2010). Generation Y Learning in the 21st Century: Integration of Virtual Worlds and Cloud Computing Services. In Z. Abas et al. (Eds.), Proceedings of Global Learn Asia Pacific 2010 (pp. 1888-1897). AACE, Penang, Malaysia, May 17 20, 2010.

[11] COD (2011). Cambridge google widgets. Last retrieved July $28^{\text {th }}$, 2011 from http://dictionary.cambridge.org/freesearch.html.

[12] Collins, A. (2009). Rethinking Education in the Age of Technology. New York, NY: Teachers College Press.

[13] Collins (2011). Collins dictionary and thesaurus. Last retrieved July 28 ${ }^{\text {th }}, 2011$ from http://www.collinslanguage.com/extras/ dictionary.aspx.

[14] Creeger, M. (2009). Cloud Computing: An Overview. Acmqueu, June 1, 2009, last retrieved April $3^{\text {rd }}, 2012$ from http://queue.acm.org/detail.cfm?id=1554608

[15] Curran C. (1976). Counseling-Learning in Second Languages. Apple River Press: Apple River, USA.

[16] Google Apps (2011). Google apps for free. Last retrieved July $28^{\text {th }}, 2011$ from http://www.google.com/apps/intl/en/group/ index.html

[17] Google Gadgets (2011). Google desktop gadgets. Retrieved July $28^{\text {th }}, 2011$ from http://desktop.google.com/plugins/.

[18] Gütl, C. (2008). Moving towards a Fully-Automatic Knowledge Assessment Tool. iJET International Journal of Emerging Technologies in Learning, Vol 3, No 1 (2008), and http://onlinejournals.org/i-jet/article/view/172/240

[19] Gütl, C., \& Chang, V. (2008). Ecosystem-based Theoretical Models for Learning in Environments of the 21st Century. International. Journal of Emerging Technologies in Learning (iJET), Vol 3 (2008), 50-60

[20] Gütl, C. (2011). The Support of Virtual 3D Worlds for enhancing Collaboration in Learning Settings. In Francesca Pozzi and Donatella Persico (Eds.) Techniques for Fostering Collaboration in Online Learning Communities: Theoretical and Practical Perspectives, IGI Global, 2011, 278-299.

[21] Gütl, C., Lankmayr, K., Weinhofer, J., \& Höfler, M. (2011). Enhanced Approach of Automatic Creation of Test Items to foster Modern Learning Setting. Electronic Journal of e-Learning, 9, 1 , ECEL 2010 special issue Apr 2011, 23- 38.

[22] Hafner, C. A., \& Miller, L. (2011). Fostering Learner Autonomy in English for Science: A Collaborative Digital Video Project in a Technological Learning Environment. Language Learning \& Technology, 15, 3 (Oct 2011), 68-86.

[23] Hanson-Smith, E., \& Rilling, S. (Eds.) (2007). Learning Language through Technology. Tesol, Baltimore, MD, USA: 2007.

[24] Hayes, G. (2009). The Virtual Worlds Hype Cycle for 2009. URL http://www.muvedesign.com/the-virtual-worlds-hype-cyclefor-2009/ (Access date: 12 June 2009) 
[25] Hemard, D. P. (1997). Design principles and guidelines for authoring hypermedia language learning applications. System, 25(1), 9-27. http://dx.doi.org/10.1016/S0346-251X(96)00057-7

[26] Hubbard, P. \& Levy, M. (Eds.). 2006. Teacher Education in CALL. Amsterdam: John Benjamins.

[27] JSpell (2011). Spell checker. Last retrieved July 28 ${ }^{\text {th }}, 2011$ from http://www.jspell.com/public-spell-checker-embed2.html.

[28] Kabilan, M. K., Ahmad, N., \& Zainol Abidin, M. J. (2010).Facebook: An onlineenvironment for learning of English in institutions of higher education? The Internet and Higher Education, 13, 4 (December 2010), 179-187. http://dx.doi.org/10.1016/ j.iheduc.2010.07.003

[29] Krashen, S. (1981). Second Language Acquisition and Second Language Learning. Pergamon Press Inc.

[30] Küfi, E. O., \& Özgür, B. (2009). Web 2.0 in learning english: the student perspective. Procedia - Social and Behavioral Sciences, 1(1), 326-330. Available from http://www.sciencedirect.com/ science/article/B9853-4VVXVR8-20/2/5393b26e439c5dbcb0f5b 53704028fe3 (World Conference on Educational Sciences, Nicosia, North Cyprus, 4-7 February 2009 - New Trends and Issues in Educational Sciences). http://dx.doi.org/10.1016/j.sbspro.2009. 01.061

[31] Lab Pix (2011). Personalized web gadgets 'widgets'. Retrieved July $28^{\text {th }}$, 2011from http://www.labpixies.com/.

[32] Lanthaler, M., \& Gütl, C. (2011). Aligning Web Services with the Semantic Web to Create a Global Read Write Graph of Data. Proceedings of the 9th IEEE European Conference on Web Services, ECOWS 2011, Lugano, Switzerland, September 14-16, 2011, pp. 15-22. http://dx.doi.org/10.1109/ECOWS.2011.17

[33] Larsen-Freeman, D. (2011). Techniques and Principles in Language Teaching. Oxford: Oxford University Press.

[34] Lee, L. (2011). Blogging: Promoting learner autonomy and intercultural competence through study abroad. Language Learning \& Technology, 15(3), 87-109.

[35] Levy, M. (1997). Computer-Assisted Language Learning: Context and Conceptualization. Oxford; Oxford University Press.

[36] Liferay (2012). Official Website. Liferay, last retrieved Feb. $9^{\text {th }}$, 2012 from http://www.liferay.com/home

[37] Liferay (2012b). OpenSocial and Gadgets. Liferay, laste retrieved Feb. 9 ${ }^{\text {th }}, 2012$ from http://www.liferay.com/de/community/wiki//wiki/Main/Liferay+6.0\%2C\%20OpenSocial+and+Gadgets

[38] Liferay (2012b). I-Frame and Portlet. Liferay, laste retrieved Feb. $9^{\text {th }}, 2012$ from http://www.liferay.com/de/community/wiki//wiki/Main/Iframe+Portlet

[39] Liferay (2011). Liferay developer guide 6.0. Liferay, last retrieved July $27^{\text {th }}$, 2011 from http://docs.liferay.com/portal/6.0/official/ liferay-developer-guide-6.0.pdf.

[40] Lingro (2011). Lingro dictionary. Last retrieved July 28 ${ }^{\text {th }}$, 2011 from http://lingro.com/.

[41] Liu, M, Moore, Z, Graham, L and Lee, S. (2002). A look at the research on computer-based technology use in second language learning: A review of the literature from 1990 - 2000. Journal of Research on Technology in Education , 34(3): 250-273.

[42] MySQL (2012). MySQL - The world's most popular open source database. Oracle, last retrieved Feb. $9^{\text {th }}, 2012$ from http://www.mysql.com/

[43] Özgür Küfi, E., \& Özgür, B. (2009). Web2.0 in learning English: the student perspective. Procedia - Social and Behavioral Sciences, 1,1 (2009), 326-330.

[44] Pica, T (1994). Research on Negotiation: What Does It Reveal About Second-Language Learning Conditions, Processes, and Outcomes? Language Learning 443, September 1994, pp. 493527. http://dx.doi.org/10.1111/j.1467-1770.1994.tb01115.x

[45] ROLE (2012). Official Website. Role project, last retrieved Feb. $9^{\text {th }}, 2012$ from http://www.role-project.eu/

[46] Safran, C., Helic, D., \& Gütl, C. (2007). E-Learning practices and Web 2.0. In Proc. of ICL 2007, Villach, Austria, September 2007.

[47] Skinner, B.F (1954). Verbal Behaviour. New York: AppletonCentury-Crofts.

[48] Sommerville, I. (2004). Software Engineering. Addison Wesley, 7 edition, Jun 2004

[49] Spolsky, B., \& Hult, F. M. (Eds.) (2008). The Handbook of Educational Linguistics. Blackwell Publisching, 2008.

[50] Text2Speech (2011). Online text to speech converter. Last retrieved July $28^{\text {th }}$, 2011 from http://www.text2speech.org/.

[51] TOMCAT (2012). Apache Tomcat. Apache Software Foundation, last retrieved Feb. 11 ${ }^{\text {th }}$. 2012 from http://projects.apache.org/projects/tomcat.html

[52] UBUNTU (2012). Ubuntu official website. Ubuntu, last retrieved Feb. 11 ${ }^{\text {th }}, 2012$ from http://www.ubuntu.com/

[53] Yuan, J. (2010). Liferay Portal 6 Enterprise Intranets: Build and maintain impressive corporate intranets with Liferay. Birmingham, UK: Packt Publishing Ltd.

\section{AUTHORS}

C. Gütl is with the Institute of Information Systems and Computer Media, Graz University of Technology, Graz, Austria (cguetl@iicm.edu).

V. Chang is with School of Information Systems, Curtin University, Perth, Western Australia (Vanessa.Chang@cbs.curtin.edu.au).

A. Edwards is with University of Colima, Colima, Mexico (arted@ucol.mx).

S. Boruta is with the Institute of Information Systems and Computer Media, Graz University of Technology, Graz, Austria (stefi_b@sbox.tugraz.at).

This article is an extended and modified version of a paper presented at the International Conference on Interactive Collaborative Learning (ICL2012), held 26 - 28 September 2012, in Villach, Austria. Received 23 January 2013. Published as resubmitted by the authors 25 April 2013. 